\title{
Impact of COVID-19 on Tourism Industry: Challenges and Opportunities
}

\author{
Naipeng (Tom) $\mathrm{Bu}^{1}$, Honggen $\mathrm{Xiao}^{2}$, Haiyan Kong ${ }^{1} \&$ Feiran (Cathy) Dong ${ }^{1}$ \\ ${ }^{1}$ Business School, Shandong University, China \\ ${ }^{2}$ School of Hotel and Tourism Management, The Hong Kong Polytechnic University, Hong Kong \\ Correspondence: Feiran (Cathy) Dong, Lecturer, Business School, Shandong University, China.
}

Received: April 4, 2021

doi:10.5430/jms.v12n2p1
Accepted: May 6, 2021

Online Published: May 18, 2021

URL: https://doi.org/10.5430/jms.v12n2p1

\begin{abstract}
Purpose -Covid-19 pandemic has created a negative impact on China's national economy and social development, and the tourism industry has been hit particularly hard. This paper analyzes the current situation of tourism development in China during the pandemic, as well as the strategies and approaches adopted for tourism recovery.

Design/methodology/approach - Secondary data and in-depth interview were adopted to identify the characteristics of tourism industry and challenges posed by the pandemic on China's tourism.
\end{abstract}

Findings - This paper focuses on the diversified and personalized modern tourism and leisure needs of tourists to establish an effective tourism supply system.

Originality/value - Bassd on the practical challenges and feasible opportunities, we then discuss- relevant strategies and put forward suggestions for future tourism research and practice.

Keywords: tourism industry, COVID-19, vhallenges and opportunities, China

\section{Introduction}

Tourism is the most "sunrise industry" and is the real inexhaustible green oil (Xu, 2020). One out of eleven jobs is created by tourism $(\mathrm{Xu}, 2020)$. Every day, up to three million travelers across the international borders are contributing to the prosperity and development of the world. However, the demand for tourism, especially international tourism, is susceptible to crises. Tourism industry is vulnerable to a variety of external-variables, including political factors, natural and social environments, and economic conditions, thereby making this industry highly sensitive (Ritchie \& Jiang, 2019).

The outbreak of the 2019 novel coronavirus not only threatened the economy and health of mankind but also spread panic and anxiety across all countries, which in turn had an unprecedented impact on the global tourism industry. First, tourism is a high-risk activity. For the purpose of protecting citizens' health and maintaining the stable development of the national economy, China and many other countries have implemented strict measures to limit the movement of people to effectively curb the spread of the coronavirus, such as flight suspensions and stricter border control, which, to a certain extent, have rendered the tourism industry morbid. Second, the spread on social media of misleading and fake information regarding the pandemic only stimulates fear and hatred among people and increase their risk perception toward tourism activities, thereby greatly reducing the travel demand and consumer confidence (Zheng, Luo, \& Brent, 2020). Some studies have shown that tourists may require a long time to recover their consumption psychology and emotions after the pandemic (Yan, Zhou, \& Wu, 2018). Therefore, this public panic not only affects the current tourism development but also hinders the post-pandemic recovery of the tourism industry to a certain extent.

Therefore, the COVID-19 has posed inevitable challenges for the tourism industry. In view of this, the management of various crises, including the coronavirus pandemic, is of vital importance. After this pandemic is controlled, which measures should be taken to achieve a comprehensive recovery of tourism, how to eliminate anxiety among tourists, and how to build public confidence at the national and international levels pose problems that crisis managers need to face (Zheng, Luo, \& Brent, 2020). Meanwhile, despite significantly affecting the global tourism industry, the coronavirus pandemic may also present an important opportunity for the tourism industry to further 
reform and upgrade itself. We should not only see the huge losses caused by the pandemic but also need to rationally analyze the aforementioned opportunities on the premise of accepting our reality (Xia \& Feng, 2020).

Tourism is not only our basic enjoyment and right in our life but also an effective means to achieve the sustainable development goal set by the United Nations. Thus, an industry-wide shuffling is inevitable. The impact is not only on traditional travel agencies and hotels but also on every channel of the modern Internet supply chain. In the contents of the coronavirus pandemic, it is time to change our thinking and turn crisis into an opportunity. Tourism is primarily a service driven industry, and it should contribute to sustainable production and consumption (Xu, 2020).

This study focused on the impact of COVID-19 on tourism destination in China because China's tourism is an important part of Asian-Pacific tourism, and the revenue of which accounts for a large part of the global share. Thus, identifying the influence of COVID-19 on tourism destination in China can not only protect national health as well as maintain steady economic performance, but also conduce to sustainable production as well as consumption. Secondary data and in-depth interview were analysed to identify the characteristics of tourism industry and challenges posed by the coronavirus pandemic on China's tourism. Based on the practical challenges and feasible opportunities, we then discuss relevant strategies and put forward suggestions for future tourism research and practice.

\section{Theoretical Background}

In consideration of the challenge posed by COVID-19 on tourism, the management of various crisis, including the pandemic itself, is very important so as to eliminate tourists' panic, to build public confidence as well as promote the comprehensive recovery of tourism.

Rosenthal and Pijnenburg (1990) suggested that crisis management has gained practical significance since 1960s, and it is defined as a method of influencing direction that events take both during and after a crisis in order to restore the status quo promptly, minimize economic losses, maintain public confidence. Ritchie (2009) implicated that there are three dimensions of effective crisis and disaster management, namely, planning and preparedness activities before a crisis or disaster, response to, or management of, a crisis or disaster when it occurs, and a final solution to a new or improved state after the crisis or disaster ends. Further, Nicolette de Sausmarez (2007) argued that the period after the crisis deserves most attention, and tourism is worth special consideration for its resilience when infrastructure is not seriously damaged. So, tourism sector can potentially act as a vehicle for the economic recovery after the crisis.

In terms of tourism in crisis management, six factors have been identified, namely, communication, the media, marketing strategies and messages, disaster management or future preparedness, destination image and reputation, and tourist behavior (Mair, Ritchie, \& Walters, 2016).

As for Communication, receiving precise and update information from emergency managers is important for organizations and individual business (Hystad \& Keller, 2008). When a disaster occurs, media can be misleading (Peters \& Pikkemaat, 2005), but it can also help hastening the delivery of state and municipal funds to replace and restore tourism infrastructure (Tsai and Chen, 2010). Moreover, marketing and promotions is essential in a destination's recovery after a crisis (Hystad \& Keller, 2008). Meanwhile, Mair, Ritchie, and Walters (2016) noticed that in many instances, there tended to be a lack of formal crisis or emergency management plans, and thus management plans and future preparedness are important after experiencing crises. Also, as they point out, for the attributes of being intangible and thus hard to achieve, destination image and reputation bring difficulty to post-crisis recovery. Additionally, tourists in the destination during a disaster are at a greater risk because of their lack of local knowledge on what to do with the danger (Ritchie, 2008), and tourists will cancel their travel plans when they perceive a high degree of physical risk (Wang, 2009). As Mair, Ritchie, \& Walters (2016) point out, for the attributes of being intangible and thus destination image and reputation bring difficulty to post-crisis recovery.

The study aims to provide strategies for the recovery of the tourism industry post-COVID19, and points out the impact of the pandemic on tourism destination and the future.

\section{Chinese Tourism Under the Influence of COVID-19}

COVID-19, the epidemic that has been widespread since the beginning of 2020, has called a halt to the global tourism industry. As far as China is concerned, $86.8 \%$ of the tourism enterprises are still in standstill until March 21, 2020. The complete halt of the tourism industry has resulted in a loss of more than 2.6 billion USD per day. In other words, the breadth and depth of the impact of the pandemic have no precedent. Tourism, being characterized by the comprehensive and cross-field development, has a strong leading role. Therefore, the tourism industry is particularly sensitive to the changes in external environment. The emergence of major crisis events affects the development of 
the tourism industry. The outbreak of the epidemic is a clear example. On the basis of the estimation of Center for Recreation and Tourism Research of Peking University, the national tourism industry will lose nearly 3 trillion yuan in 2020 (Business School Magazine, 2020). At the same time, in China's tourism industry, the number of direct employment is 28.26 million; the number of indirect employment is 51.65 million; and combined they account for $10.29 \%$ of the total employment of China. The "cold winter" that the tourism industry encountered may also have a negative influence on employment (Business School Magazine, 2020).

For global tourism, China is the main source country, and its contribution rate to world tourism is more than $12 \%$. The impact of the epidemic on world tourism is huge (Bao, 2020). On the basis of incomplete statistics, COVID-19 would reduce the short-term tourism revenue of Southeast Asia countries, which relies mainly on China's overseas travelers by $30 \%$. For example, in Thailand, China is the first largest tourist source country, and the consumption of Chinese tourists accounts for 2.7\% of Thailand's GDP. From January 24 to 31, 2020, the number of Chinese tourists reduced by $60 \%$, and 294 million US dollars was lost in one week. Thailand's revenue in tourism is expected to fall by 9.7 billion US dollars from January to June, 2020 (Bao, 2020). Additionally, in 2019, Chinese tourists accounted for $7 \%$ of the total number of tourists in the United States, and the consumption of Chinese tourists in the United States was worth 34 billion US dollars. The United States will reduce its tourism economic income by 10.3 billion US dollars due to the COVID-19 outbreak. In terms of the total impact of the epidemic, the global tourism development will slow down this year, and the growth rate will form a zero growth or negative growth trend (Bao, 2020).

Many domestic industry delegates have said that in comparison with the international long-term products crossing national boundaries, the other trend of the market is the short-distance tourism products and the short-distance products in the domestic market. Regardless of the tourism in their own city or suburban tourism, rural tourism and other short-haul tourism products should experience first recovery in post-Covid19 period. Since the Wenchuan earthquake in 2008, Sichuan tourists' mentality_-Living is Good"-is a good reference point (Xu, 2020).

After the pandemic, the tourism industry must guard against going back to the old business model. We should change our thinking mode and take the initiative to transform the business model of the tourism industry. During the pandemic, tourist attractions should take the initiative and innovate, shorten the recovery cycle as much as possible, get out of the development trough as soon as possible, and survive the epidemic by means of product pre-sale and orderly return to work. Group tourism, especially long-distance group tourism, will take some time to resume. A large recovery will be observed in family travel, especially in self-driving, and the recovery of long-distance tour charter and special trains will be relatively slow. From the perspective of travel distance, the recovery of tourism market is from short distance to long distance. From the perspective of tourists' psychology, tourists will generally pay more attention to sanitation and disinfection and focus on environmental safety and wild animals. From the perspective of travel destination, rural tourism will be more popular, and leisure vacation will become a choice for more tourists. Therefore, outdoor skiing and summer health and wellness may become a new hot spot, and forest convalescence and hot spring health and wellness, as one of health products, will inevitably resume. Although the flow of tourists will not be too large in the first to second quarter 2020 under the impact of the epidemic, the hot spring health and wellness will have a strong market attraction. Therefore, coast in summer and hot spring in winter will take a lion's share of holiday products (Bao, 2020).

The COVID-19 pandemic is an unprecedented crisis for the domestic tourism industry and has led to huge losses to the domestic tourism industry. However, the crisis is also an opportunity. How to reduce the loss and stand out in this special epidemic situation is what every scenic spot needs to consider. China's tourism market is vast and is developing rapidly, and the number and demand of tourists are numerous and increasing. Only by seizing the opportunity brought by the crisis can we quickly recover our vitality, stop the loss in time, and strive for greater profits in the future. The outbreak of the epidemic reflects the vulnerability and the rigid demand of tourism. However, starting from the connotation of the crisis, danger and opportunity coexist. This epidemic has also brought innovative models that provide a broad mode of thinking for future development. In the current hardship, how to weather the storm is also a primary issue of scenic spots.

\section{Strategies for the Recovery of the Tourism Industry Under COVID-19}

As analyzed above, the coronavirus pandemic is a crisis for tourism industry, and it can also be an opportunity. During this period, tourism attractions should optimize their own states, pay attention to the epidemic situation in time, understand the demand of tourism market, and adjust the enterprise strategy in time to minimize the negative effect of the epidemic on tourism attractions. Therefore, various measures are supposed to be taken so as to control the loss and stand out in this epidemic situation. 


\subsection{Adopting New Technology}

During the epidemic, the entity tourism industry was in halt, and some enterprises were forced to help themselves. It drives the transformation of tourism market environment and brings about the transformation of tourism industry business models. Travel behavior as well as the tourism industry are revolutionized by technological advances (Pabel, 2020). The application and upgrading of 5G technology have changed the production mode of tourism experience. As VR, AR, 3D, and 5G technologies are increasingly mature and are widely used, the tourism industry can meet the needs of consumers who cannot travel during the epidemic.

In combination with these new technologies, virtual tourism and exhibition can be realized. The 360-degree VR panoramic guide system used in the tourism attractions can also provide tourists with beautiful sceneries. Combinations, such as tourism and live telecast and short video and tourism, produce new products and new models. At present, the prosperity of live telecast market has given birth to the marketing and viewing mode of tourism and live telecast. A large number of tourism experience needs are satisfied through online live telecast of Internet celebrities. During this period, the tourism industry should strengthen innovation, provide excellent service, and improve operations. Moreover, we should improve online training, promote the concept of virtual tourism, and promote intelligent tourism.

\subsection{Innovating, Transforming, and Upgrading}

Through innovation, transformation, and upgrading, crisis can be turned into an opportunity. Single business activity and lack of innovation are common problems in tourism attractions and thus restrict the sustainable development of this industry. The epidemic is a test for tourism attractions. Those tourism attractions with single business activity are often hit harder, whereas those with online service ability, online sales system, and relatively diversified products and services can develop e-commerce service that relies on their advantages in the channel, thereby making up for the loss of main business income. Therefore, tourism attractions should initially broaden their income sources and reduce the restrictions of physical space on the development of scenic spots. For example, a series of virtual tourism products can be launched to broaden the business scope, which can increase the revenue and improve the popularity of tourism attractions. Second, facilities and activities for health and wellness, recuperation, and sports should be increased to satisfy the consumption demand of tourists after the epidemic.

Additionally, The managers of tourism attractions should actively adopt online office mode during this period of time to improve relevant systems, compile and print training materials, and organize employees to strengthen tourism business learning in the manner of self-learning. The marketing personnel of tourism attractions should keep communication with various channels, timely understand the market trends, conduct information collection and judgment, launch targeted tourism products, actively plan summer tourism marketing, select the time and method of marketing, and make full preparation for rapidly opening the market after the normal operation resumed. However, it is also an opportunity for precipitation development. Innovation and uniqueness are important ways for tourism attractions to entice tourists. Tourism attractions can upgrade their scenic spots and products during this long holiday and attempt to transform or actively develop cultural and creative products.

\subsection{Strengthening the Cooperation}

The COVID-19 outbreak has already brought significant impacts to nearly every society and industry (Wen et al., 2020). Therefore, the recovery of tourism and scenic spots requires strengthening the cooperation with upstream and downstream enterprises and relevant service organizations. In the tourism attraction industry, scenic spot enterprises are suggested to communicate with their counterparts to avoid the vicious competition of homogeneity, strengthen the cooperation among scenic spots by taking the development of the entire market as the overall situation, and design and launch linkage line products to strive for the maximization of the benefits of regional tourism industry.

In the face of epidemic, the vulnerability of the tourism industry and scenic spots are clear. The epidemic is a crisis and is an alarm against the tourism industry. Scenic spot enterprises with strong innovation ability can innovate and reform during this epidemic, whereas those enterprises with insufficient innovation ability and single business activity are easily hit. Therefore, the epidemic may be a double-edged sword and an elimination mechanism against scenic spots and even the entire tourism industry.

\section{Impact of the Pandemic on Tourism Destination and the Future}

From the perspective of travel distance, the post pandemicc tourism market recovery should be from near to far. Process of recovery from suburban tourism to long-distance tourism and processes of adaptation from less to more people are available. After the epidemic, short-distance tourists will be the majority, whereas long-distance travelers will gradually increase. In areas with large physical and geographical scale and areas with less severe epidemic, 
tourism will resume greatly. In terms of tourism destination, a huge growth will be observed in holiday tourism and natural health and wellness tourism. Urban tourism consumption will be active, and rural tourism around the city will be popular. According to Pan, Wang and Ryan's (2021) research carried out in Beijing, more senior citizens prefer urban locations for their holiday, while rural locations are also attractive to the elders for their unpolluted state. Remote places with fewer people may become new tourism hot spots. Leisure vacation may also become a choice of many tourists.

From the perspective of tourists' psychology, the epidemic may make tourists pay more attention to, care about, and be sensitive to sanitation and disinfection, environmental safety, and wild animals. According to Williams, Wassler and Ferdinand (2020), tourists' risk perception is likely to be influenced by a destination's adoption (or lack) of a type of vaccine. Therefore, on the one hand, tourist attractions can take active measures in sanitation and disinfection, in tourist guidance and maximum carrying capacity restriction and in enhancing tourists' confidence. On the other hand, tourist attractions are supposed to avoid bad publicity caused by poor sanitation, poor environmental pollution, and eating wild animals without caution. In terms of future development, the epidemic may force the upgrading of smart tourism to accelerate. After the epidemic, intelligent tourism will become an important means of prevention and control in the critical period of scenic spots and may be normal in the future. If scenic spots must set the carrying capacity reasonably and scientifically, they are supposed to utilize the intelligent tourism platform to effectively take ticket booking, intelligent guidance, and other means to scientifically divert and guide tourists. Accordingly, the epidemic makes scenic spot managers realize the importance of intelligence. Tourism is the embodiment of people's pursuit of a better way of life. It is the sunrise industry, and its development cannot be stopped by a crisis.

\section{Limitations and Future Study}

The conclusions of this study are largely based on secondary data sources. Therefore, the findings are contingent upon the availability and quality of data. Future studies are encouraged to conduct and develop the empirical research on impact of COVID-19 on Tourism Industry through diverse research methods.

\section{Acknowledgment}

The author would like to thank the support of the National Social Science Fund of China (20BJY131), Shandong Social Science Fund (20CLYJ35).

\section{References}

Bao, J. G. (2020). It will take about 1 year for the tourism industry to recover. Retrieved 6 July 2020, from https://wap.peopleapp.com/article/5230129/5133052?from=timeline\&isappinstalled=0

Business School Magazine. (2020). Outbreak | tourism: the daily loss of more than 17 billion, look forward to the days of retaliatory rebound. Retrieved 6 July 2020, from https://ishare.ifeng.com/c/s/7tq8cZff24Q

Hystad, P., \& Keller, P. (2008). Towards a destination tourism disaster management framework: Long-term lessons from a forest fire disaster. Tourism Management, 29(1), 151-162. https://doi.org/10.1016/j.tourman.2007.02.017

Mair, J., Ritchie, B. W., \& Walters, G. (2016). Towards a research agenda for post-disaster and post-crisis recovery strategies for tourist destinations: a narrative review. Current Issues in Tourism, 19(1), 1-26. https://doi.org/10.1080/13683500.2014.932758

Nicolette, de S. (2007). The Potential for Tourism in Post-crisis Recovery: Lessons from Malaysia's Experience of the Asian Financial Crisis. Asia Pacific Business Review, 13(2), 277-299. https://doi.org/10.1080/13602380601045587

Pabel, A. (2020). Guest editorial: towards a better understanding of technology in tourism. Journal of Hospitality Tourism Management, 42, 256-257. https://doi.org/10.1016/j.jhtm.2020.01.013

Pan, Y., Wang, X., \& Ryan, C. (2021). Chinese seniors holidaying, elderly care, rural tourism and rural poverty alleviation programmes. Journal of Hospitality and Tourism Management, 46, 134-143. https://doi.org/10.1016/j.jhtm.2020.09.010

Peters, M., \& Pikkemaat, B. (2005). Crisis management in alpine winter sports resorts - the 1999 avalanche disaster in Tyrol. Journal of Travel \& Tourism Marketing, 19(2), 9-20. https://doi.org/10.1300/J073v19n02_02

Ritchie, B. W. (2008). Tourism disaster planning and management: From response and recovery to reduction and readiness. Current Issues in Tourism, 11(4), 315-348. https://doi.org/10.1080/13683500802140372

Ritchie, B. W. (2009). Crisis and disaster management for tourism. Clevedon: Channel View. https://doi.org/10.21832/9781845411077 
Ritchie, B. W., \& Jiang, Y. (2019). A review of research on tourism risk, crisis and disaster management: launching the annals of tourism research curated collection on tourism risk, crisis and disaster management. Annals of Tourism Research, 79. https://doi.org/10.1016/j.annals.2019.102812

Rosenthal, U., \& Pijnenburg, B. (1990). Simulation-oriented scenarios: an alternative approach to crisis decisionmaking and emergency management. Contemporary Crises, 14, 277-283. https://doi.org/10.1007/BF00728501

Tsai, C., \& Chen, C. (2010). An earthquake disaster management mechanism based on risk assessment information for the tourism industry. Tourism Management, 31, 470-481. https://doi.org/10.1016/j.tourman.2009.05.008

Wang, Y. (2009). The impact of crisis events and macroeconomic activity on Taiwan's international inbound tourism demand. Tourism Management, 30, 75-82. https://doi.org/10.1016/j.tourman.2008.04.010

Wen, J., Kozak, M., Yang, S., \& Liu, F. (2020). Covid-19: potential effects on Chinese citizens' lifestyle and travel. Tourism Review, (ahead-of-print). https://doi.org/10.1108/TR-03-2020-0110

Williams, N. L., Wassler, P., \& Ferdinand, N. (2020, December). Tourism and the COVID-(Mis) infodemic. Journal of Travel Research. https://doi.org/10.1177/0047287520981135

Xia. J. C., \& Feng. X. X. (2020). The Impact of Novel Coronavirus Outbreak on Tourism Industry and the Countermeasures. China's Circulation Economy, 34(3), 3-10.

Xu, J. (2020). What will happen to Asia-Pacific tourism under the impact of COVID-19?. Retrieved 6 June 2020, from https://weibo.com/u/1025891392?is_all=1

Yan, Q., Zhou. S., \& Wu, S. (2018). The influences of tourists' emotions on the selection of electronic word of mouth platforms. Tourism Management, 66, 348-363. https://doi.org/10.1016/j.tourman.2017.12.015

Zheng, D., Luo, Q., \& Ritchie, B. W. (2020). Afraid to travel after COVID-19? Self-protection, coping and resilience against pandemic 'travel fear'. Tourism Management, 83. https://doi.org/10.1016/j.tourman.2020.104261

\section{Copyrights}

Copyright for this article is retained by the author(s), with first publication rights granted to the journal.

This is an open-access article distributed under the terms and conditions of the Creative Commons Attribution license (http://creativecommons.org/licenses/by/4.0/). 